\title{
The effects of photoperiod and temperature on embryonic diapause termination in the hermit crab Pagurus nigrofascia
}

\author{
Shinji Mishima ${ }^{1}$, Satoshi Kobayashi ${ }^{2}$, Katsumasa Yamada $^{3} \&$ Yasuhisa Henmi $^{3, *}$ \\ ${ }^{1}$ The Ultramicroscopy Research Center, Kyushu University, 744 Motooka Nishi-ku, Fukuoka 819-0395, Japan \\ ${ }^{2}$ Department of Applied Biological Sciences, Faculty of Agriculture, Saga University, 1 Honjo, Saga 840-8502, Japan \\ ${ }^{3}$ Aitsu Marine Station, Center for Water Cycle, Marine Environment, and Disaster Management, Kumamoto University, \\ Matsushima, Kami-Amakusa, Kumamoto 861-6102, Japan
}

Received 18 May 2020; Accepted 5 October 2020 Responsible Editor: Satoshi Wada

doi: $10.3800 /$ pbr.16.79

\begin{abstract}
The intertidal hermit crab Pagurus nigrofascia reproduces in March in Fukuoka, Japan. The embryos remain in diapause until October, begin to develop in November, and most broods hatch in December. This study examined the effects of photoperiod and temperature on embryonic diapause termination (EDT) in both laboratory and field conditions. Females with diapause eggs were maintained in the laboratory under three different photoperiod/temperature regimes: constant $\left(14 \mathrm{~L} / 10 \mathrm{D}, 22^{\circ} \mathrm{C}\right.$ ), decreasing photoperiod condition (from $12 \mathrm{~L} / 12 \mathrm{D}$ to $9.8 \mathrm{~L} / 14.2 \mathrm{D}, 22^{\circ} \mathrm{C}$ ), and decreasing temperature condition $\left(14 \mathrm{~L} / 10 \mathrm{D}\right.$, from $22^{\circ} \mathrm{C}$ to $\left.10^{\circ} \mathrm{C}\right)$. The EDT date was compared among four groups: the above three experimental groups and the field group. The dates at which $>50 \%$ of females possessed eggs after the EDT were November 10 (constant), October 30 (decreasing photoperiod), September 27 (decreasing temperature), and November 4 (field). The mean duration until EDT was 82 days (constant), 67 days (decreasing photoperiod), and 36 days (decreasing temperature). Diapause was significantly shorter under both the decreasing photoperiod and the decreasing temperature conditions compared to the constant. Thus, EDT was strongly affected by temperature but weakly altered by photoperiod. This study is the first to report the influence of photoperiod and temperature on EDT in decapod crustaceans.
\end{abstract}

Key words: embryonic diapause termination, intertidal hermit crab, Pagurus nigrofascia, photoperiod, temperature effects

\section{Introduction}

Pagurus nigrofascia is a hermit crab that inhabits intertidal boulder shores and has only been recorded in a few sites in Japan (Komai 1996). In Hakodate, northern Japan, $P$. nigrofascia females produce a brood in May and incubate it for 9 months until the eggs hatch in February (Goshima et al. 1996). This 9-month incubation period is particularly long for hermit crabs inhabiting intertidal areas (Wada et al. 2000, 2005). In Fukuoka, southern Japan, females produce a brood in March, and the eggs hatch in December after the 9-month incubation period (Mishima \& Henmi 2008). Eight months after spawning, the eggs become dormant in the blastula stage (yolk-filled, with-

*Corresponding author: Yasuhisa Henmi; E-mail, henmi@kumamoto-u. ac.jp out a blastodisc), a strategy known as embryonic diapause (Mishima \& Henmi 2008).

The term 'diapause' has been widely used in entomology but had not been applied to crustaceans until recently (Stross \& Hill 1965). Most crustacean species exhibiting embryonic diapause belong to the classes Branchiopoda, Maxillopoda, and Malacostraca (Hairston \& Cáceres 1996). The crayfish Astacus astacus has a diapause of 3-4 months, and the eggs show no change between the blastoderm formation and the endomesodermal embryo (Cukerzis 1988). Wear (1974) reported egg diapause in the spider crab Hyas coarctatus and the masked crab Corystes cassivelaunus. The snow crab Chionoecetes opilio in the Gulf of St. Lawrence, Canada, has two distinct diapause periods: the first occurs during the gastrula stage and lasts for 6 months, and the second ensues during eye-pigment formation and lasts for 3-4 months (Moriyasu \& Lanteigne 1998). There is 
also a 1-month diapause during the reduced yolk stage in $C$. opilio in the eastern Bering Sea (Webb et al. 2007).

The hermit crab $P$. alatus inhabits the Mediterranean Sea at depths of 350-450 m, and ovigerous females occur throughout the year, except during March. The eggs are without eye pigments from April to September during a possible diapause stage (Mura et al. 2006). Ovigerous $P$. proximus females are found from December to August in the subtidal zone of Vostok Bay in the Sea of Japan, and their embryos remain at an early developmental stage until May (Kornienko et al. 2019). Among the intertidal decapod crustaceans, only $P$. nigrofascia are known to have an embryonic diapause stage, and this stage occurs during summer ('aestivation'), as opposed to winter ('hibernation'), which is observed in the aforementioned freshwater or deep-sea decapods.

Very few studies have tried to clarify the control mechanisms of diapause in decapods. Westin \& Gydemo (1986) showed that the duration of egg development decreased from 9 months to 4 months under an experimental hightemperature condition in the noble crayfish Astacus astacus, and in some Chionoecetes cold water crabs, diapause is directly related to temperature (Moriyasu \& Lanteigne 1998, Webb et al. 2007). It is not yet evident whether environmental factors other than temperature affect the duration of diapause in decapod embryos, although photoperiod has been shown to affect embryonic diapause termination (EDT) in many other crustaceans (Stross 1969, Miller et al. 1991, Alekseev \& Starobogatov 1996). In the flagellates, moreover, photoperiod and temperature are two major factors affecting cyst germination (Bravo \& Anderson 1994, Imai \& Yamaguchi 2012), although cyst formation is markedly different from embryonic diapause. The onset of embryonic diapause in P. nigrofascia may be controlled by intrinsic factors since the eggs become dormant at early stage; whereas the termination of diapause could be controlled by intrinsic and/or external factors. In this study, we examined the influence of external factors, specifically photoperiod and temperature, on EDT in P. nigrofascia.

\section{Materials and Methods}

\section{Incubation conditions}

We conducted the experiment from August 22 to December 29, 2007 (129 days). P. nigrofascia were collected on August 21, 2007, from Wajiro beach $\left(33^{\circ} 40^{\prime} \mathrm{N}\right.$, $\left.130^{\circ} 25^{\prime} \mathrm{E}\right)$, Fukuoka, Japan. Each ovigerous female $(\mathrm{n}=120)$ was individually placed into a $300 \mathrm{~mL}$ beaker containing $200 \mathrm{~mL}$ of seawater and randomly divided into the three experimental groups $(\mathrm{n}=40 \mathrm{crabs}$ each). Each group was housed in a separate incubator (BITEC-300, Shimadzu Rika Institute Co., Ltd., Japan) that was illuminated using a straight daylight fluorescent tube $(20 \mathrm{~W})$ placed on the interior ceiling. The seawater in each beaker was changed weekly, and the hermit crabs were fed crushed Hikari Crest (Kyorin Co., Ltd., Japan). The incubators had photoperiod/temperature regimes as follows (see Figs. 1 \& 2): the constant condition (Group 1) was maintained on a constant $14 \mathrm{~L} / 10 \mathrm{D}$ light schedule at $22^{\circ} \mathrm{C}$ throughout the experiment; the decreasing photoperiod condition (Group 2) began on a 12L/12D light schedule, which was gradually reduced to $9.8 \mathrm{~L} / 14.2 \mathrm{D}$, and maintained at $22^{\circ} \mathrm{C}$ throughout the experiment; the decreasing temperature condition (Group 3) was maintained on a $14 \mathrm{~L} / 10 \mathrm{D}$ light schedule initially at $22^{\circ} \mathrm{C}$ and gradually reduced to $10^{\circ} \mathrm{C}$. Differences in duration until EDT among

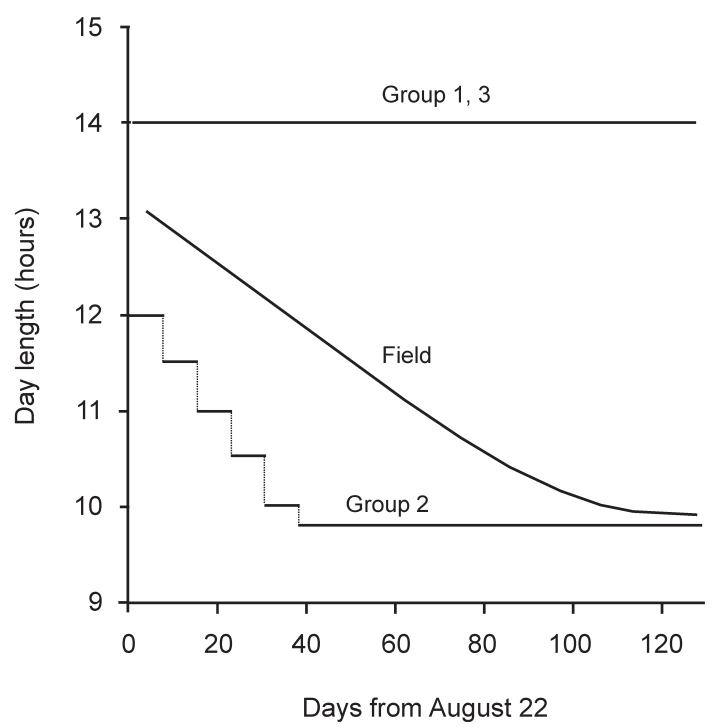

Fig. 1. The photoperiod regime in three experimental groups: Group 1 (constant), Group 2 (decreasing photoperiod condition), Group 3 (decreasing temperature condition) and in the field (data from National Astronomical Observatory of Japan).

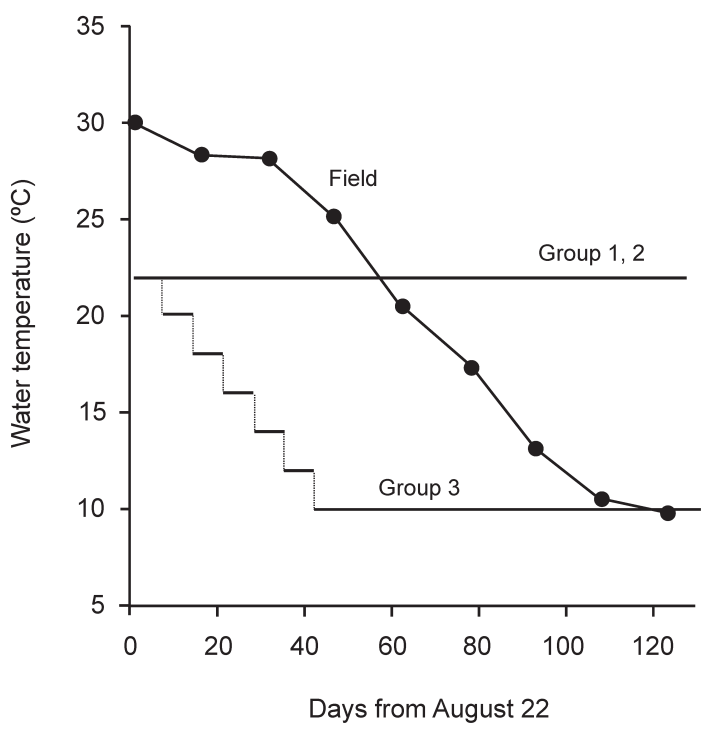

Fig. 2. The temperature regime in three experimental groups: Group 1 (constant), Group 2 (decreasing photoperiod condition), Group 3 (decreasing temperature condition) and in the field. 


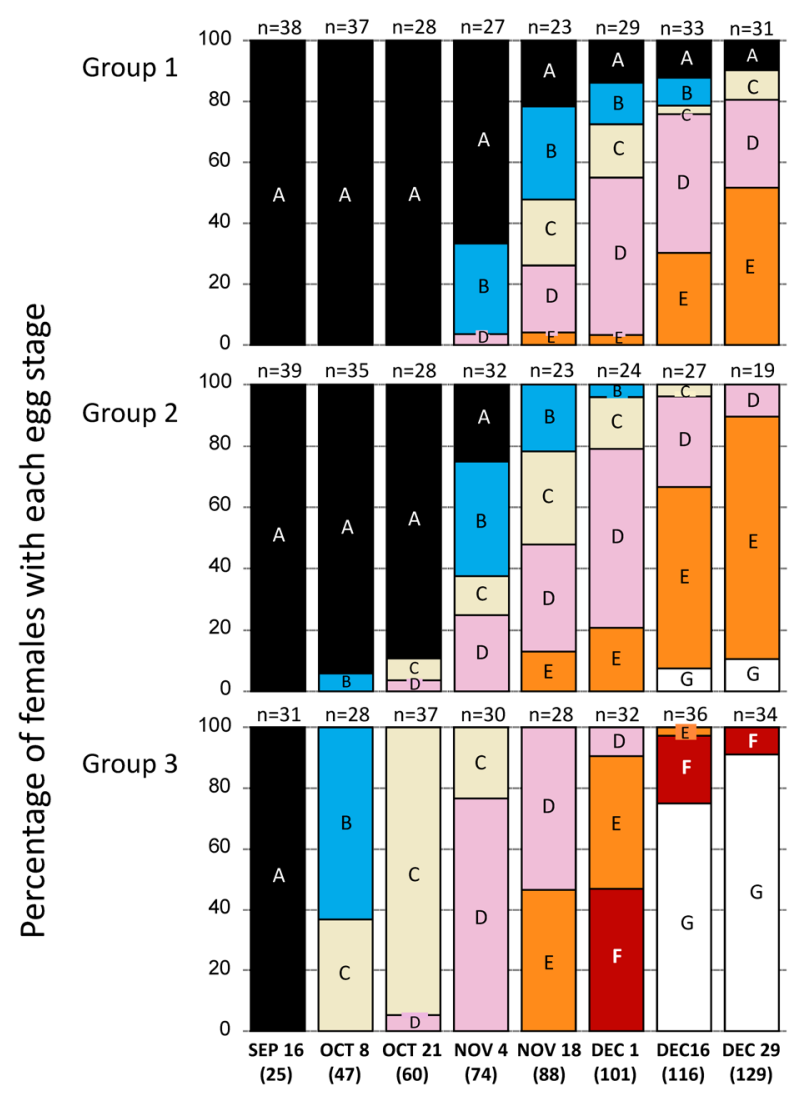

Fig. 3. The percentage of females with each egg stage in Group 1 (constant), Group 2 (decreasing photoperiod condition), and Group 3 (decreasing temperature condition). The number of days from August 22 is shown in parentheses.

experimental groups (Group 1-3) were evaluated using Cox proportional-hazards regression analysis (Cox, 1972, Yamada et al. 2018) using R ver. 4.0.2 (http://cran.r-project. org/). The analysis included experimental groups and dates (nested within groups) as explanatory variables.

\section{Ecological basis of incubation conditions}

In Fukuoka, the day length varies from 14.4 hours (at summer solstice) to 9.9 hours (at winter solstice) (National Astronomical Observatory of Japan). At the start of the experiment on August 22, the day length was approximately 14 hours, and therefore we housed Groups 1 and 3 under a $14 \mathrm{~h}$ constant light regime. Group 2 was adjusted from 12 hours of light per day, which corresponds to the autumnal equinox, to 9.8 hours, which approximates that of the winter solstice.

To determine the incubation temperature, we considered our data in 2004, which showed that the monthly mean temperature at the study site (lower intertidal) peaked at $27^{\circ} \mathrm{C}$ in August. Unfortunately, we could not sustain such a high temperature due to the difficulty of maintaining the water conditions in the beakers. Instead, we determined a temperature for Groups 1 and 2 of $22^{\circ} \mathrm{C}$, which corresponded to a mid-October temperature at the field site. We reduced the temperature of Group 3 to $10^{\circ} \mathrm{C}$, which corre- lates to field conditions in December.

\section{Determination of embryonic diapause termination}

We determined the egg developmental stages by holding the shells with tweezers under a stereomicroscope and waiting for the hermit crabs to emerge and reveal their pleopods with eggs. The egg stages (A-E), determined based on Wada et al. (1995), were measured on September 16, October $8 \& 21$, November $4 \& 18$, and December 1, 16 \& 29 (see Fig. 3). We defined Stage F as partly hatched broods, Stage G as completely hatched broods, and EDT as broods at Stage B (yolk absorption and germinal disc appearance).

\section{Comparison with the field and recording temperatures}

To confirm egg development in the field, we collected $P$. nigrofascia females on Wajiro beach on August 12, September 30, October 28, November 25, and December 24, 2007. We recorded the egg stage of each female and measured the seawater temperature at the lower tidal zone every hour using temperature data loggers (Stowaway Tidbit, Onset Computer Co., MA, USA). The mean temperature was calculated every 2 weeks (see Fig. 2).

\section{Results}

\section{Egg development and EDT in the experimental groups}

Egg development in the experimental groups is shown in Fig. 3. In each group, the number of crabs varied because of death, loss of eggs, or crabs not emerging from their shells. For instance, in Group 1 on October 21, we observed that 28 crabs had Stage A eggs, 3 crabs had lost the majority of their eggs, and 9 crabs did not emerge from their shells. In Group 1, most crabs attained EDT during the experimental period despite the constant photoperiod/ temperature conditions, but 2 crabs remained in Stage A on December 29, 2007. In Group 2, all crabs attained EDT by November 18, 2007, and in Group 3, all crabs attained EDT between September 16 and October 8, 2007.

We defined the EDT date for each female as the midpoint between the last day of Stage A and the first day of Stage B. The mean duration until EDT excluding censored data was 81.6 days in Group $1(\mathrm{n}=22), 67.4$ days in Group $2(n=23)$ and 36.0 days in Group $3(n=38)$. Durations until EDT were significantly different among all experimental groups $(\mathrm{df}=2, \beta=0.913$, Wald statistics $=42.86, p<0.001)$. The duration until EDT in Groups 2 and 3 were also significantly different from that of Group 1 (Group 2: $\mathrm{z}=1.12$, $p<0.001$; Group 3: $\mathrm{z}=5.13, p<0.001$ ).

\section{Percentage of EDT in the experimental groups and the field}

The percentage of EDT in each treatment group and in the field is shown in Fig. 4. The dates when more than half of females possessed eggs after EDT were November 10 in Group 1, October 30 in Group 2, September 27 in Group 


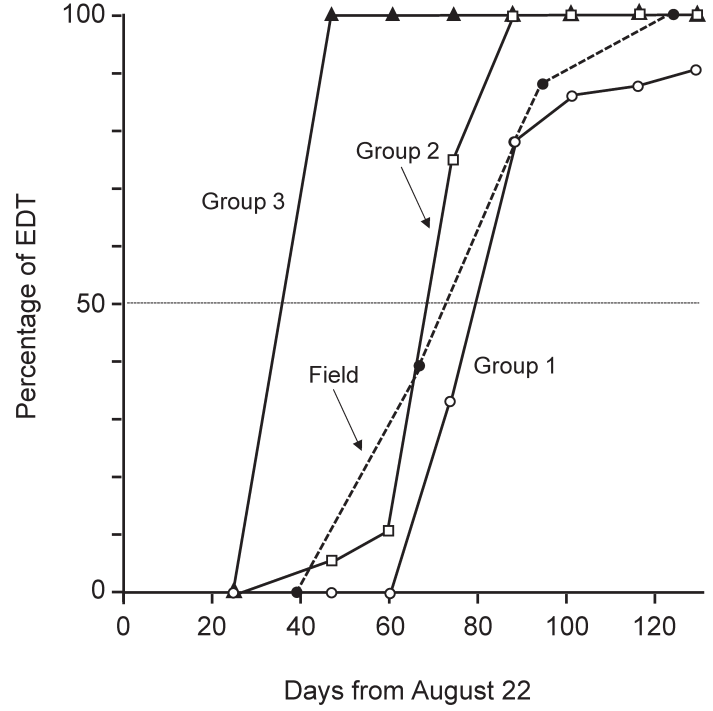

Fig. 4. The percentage of embryonic diapause termination (EDT) in three experimental groups: Group 1 ( $\bigcirc$; constant), Group 2 ( $\square$; decreasing photoperiod condition), Group 3 ( $\boldsymbol{\Delta}$; decreasing temperature condition) and in the field $(\mathbf{O})$.

3 , and November 4 at the field site. The diapause dates of Groups 1 and 2 were almost similar to that at the field site. In contrast, the embryonic diapause of Group 3 was terminated more than a month earlier than in the field.

\section{Discussion}

To our knowledge, this is the first study to experimentally test the influence of photoperiod and temperature on EDT in decapod crustaceans. We found that temperature was an obligatory condition of diapause termination for $P$. nigrofascia embryos, and that photoperiod influenced EDT to a lesser extent. In intertidal areas, temperature fluctuations are unpredictable, and photoperiodism may act as an additional influence for the timing of egg development. However, the degree to which environmental factors such as temperature and photoperiod affect EDT can vary among regions or seasons. Some organisms may respond to relative changes as opposed to absolute values of these variables, or these factors may interact with one another. For example, $P$. nigrofascia females produced broods in May in Hakodate and in March in Fukuoka, but EDT occurs in November at both locations, despite differences in climate and latitude (Goshima et al. 1996, Mishima \& Henmi 2008). In Group 1 in this study, however, most crabs attained EDT despite the constant light and temperature conditions. This can indicate the presence of regionspecific and endogenous long-range timers.

Alekseev \& Starobogatov (1996) reviewed many studies of diapause in marine, freshwater, and terrestrial crustaceans and concluded that photoperiod affected the timing of EDT in certain species (1 Anostraca species, 2 Notostraca species, 2 Cladocera species, and 3 Calanoida spe- cies). Stross (1969) reported that EDT occurred at day lengths longer than 20 hours in an arctic population of cladoceran Daphnia middendorffiana, although the EDT percentages were affected by the culture density. In these crustaceans, however, females do not directly affect the induction and termination of diapause because their eggs are released into the water immediately after spawning. In contrast, in Pleocyemata (a suborder of decapod crustaceans), the fertilized eggs are incubated until hatching. Females of $P$. nigrofascia, a species under that suborder, incubate their eggs for 9 months in Fukuoka (Mishima \& Henmi 2008), and during the summer, they move to the upper intertidal zones and estivate under boulders (Mishima \& Henmi 2008). Therefore, diapause in Pleocyemata is expected to be greatly affected by the physical environment of incubation sites.

Few available studies have examined embryonic diapause in hermit crabs. In P. alatus on the Mediterranean Sea bottom (350-450 $\mathrm{m}$ depth), all ovigerous females were shown to have eggs without eye pigments from April to September (Mura et al. 2006). Their diapause period is similar to that of $P$. nigrofascia (March-November) in Fukuoka, but the diapause timing is likely only affected by temperature, unlike that of $P$. nigrofascia, as sunlight does not reach these depths. Ovigerous $P$. proximus females were found from December to August in the subtidal areas of Vostok Bay, Sea of Japan, but the embryos remained at an early developmental stage until May (Kornienko et al. 2019), as in this region, the surface water temperature decreases to negative values in winter months and reaches $10^{\circ} \mathrm{C}$ in May. Additionally, the length of embryonic diapause varies among individuals, ranging from the absence of diapause to up to 5 months of diapause. This relates to the proportion of ovigerous females increasing from December to May, and as a result, the larval release being concentrated in June. In Hakodate, ovigerous $P$. proximus females were found from January to July $\left(7-21^{\circ} \mathrm{C}\right)$, with no embryonic diapause (Wada \& Mima 2003). Thus, the environmental signal for EDT may be temperature in $P$. proximus.

Anger (2001) suggested that embryonic diapause is an adaptation that alters the duration of the incubation period to synchronize the timing of larval release with the period of abundant primary production. In P. nigrofascia, the mass release of larvae occurs mainly in December in Hakodate and Fukuoka (Goshima et al. 1996, Mishima \& Henmi 2008), whereas in P. proximus, it occurs in early June in Vostok Bay (Kornienko \& Korn 2016). The timing of larval release differs between species but may match the season of phytoplankton blooms, which differ based on water temperature. Petersen \& Anger (1997) suggested that the embryonic diapause of the high-latitude majid Hyas araneus coordinates hatching with plankton production; such traits should be expected to evolve at high latitudes.

Although our study site was not at a high latitude, we presume that $P$. nigrofascia have evolved their long incu- 
bation period and embryonic diapause with the advance in upper intertidal zones. Females of this species widely distribute into the intertidal zones during spring, and most produce broods in March (Mishima \& Henmi 2008). During summer, females retain diapause eggs, and travel to the upper intertidal areas to estivate under boulders. They return to lower areas in autumn and release larvae in December. Thus, $P$. nigrofascia has adapted to the upper intertidal areas, where the environmental conditions are severe, by adopting the special life history traits of estivation and embryonic diapause. The present study sheds light on the influences of photoperiod and temperature on EDT in the hermit crab P. nigrofascia. However, the estivation in the intertidal areas is a unique trait even among crustaceans; therefore, further studies are required to clarify the effects of environmental conditions on the induction and termination of embryonic diapause. In addition, such studies help to clarify the adaptive significance of diapause.

\section{Acknowledgements}

We thank Akiyo Maenaka and Keiko Shiohira for their assistance in the laboratory. We also thank two anonymous reviewers for their valuable comments on the manuscript.

\section{References}

Alekseev VR, Starobogatov YI (1996) Types of diapause in Crustacea: definitions, distribution, evolution. Hydrobiologia 320: $15-26$.

Anger K (2001) The Biology of Decapod Crustacean Larvae. Crustacean Issues 14. Balkema, Lisse, 419 pp.

Bravo I, Anderson DM (1994) The effects of temperature, growth medium and darkness on excystment and growth of the toxic dinoflagellate Gymnodinium catenatum from northwest Spain. J Plankton Res 16: 513-525.

Cox DR (1972) Regression models and life tables. J Roy Stat Soc B Met 34: 187-202.

Cukerzis JM (1988) Astacus astacus in Europe. In: Freshwater Crayfish: Biology, Management, and Exploitation (eds Holdich DM, Lowery RS). University Press, Cambridge, pp. 309-340.

Goshima S, Wada S, Ohmori H (1996) Reproductive biology of the hermit crab Pagurus nigrofascia (Anomura: Paguridae). Crustacean Research 25: 86-92.

Hairston NG, Cáceres CE (1996) Distribution of crustacean diapause: micro- and macroevolutionary pattern and process. Hydrobiologia 320: 27-44.

Imai I, Yamaguchi M (2012) Life cycle, physiology, ecology and red tide occurrences of the fish-killing raphidophyte Chattonella. Harmful Algae 14: 46-70.

Komai T (1996) Pagurus nigrofascia, a new species of hermit crab (Decapoda: Anomura: Paguridae) from Japan. Crustacean Research 25: 59-72.

Kornienko ES, Korn OM (2016) A key for the identification of the zoeae of common species of hermit crabs (Decapoda:
Paguroidea) of Vostok Bay, the Sea of Japan. Russ J Mar Biol 42: 419-426.

Kornienko ES, Selin NI, Korn OM (2019) Population and reproductive characteristics of the hermit crab Pagurus proximus Komai, 2000 (Decapoda: Anomura: Paguridae) in the northern part of the species range. J Mar Biol Assoc UK 99: 101-109.

Miller CB, Cowles TJ, Wiebe PH, Copley NJ, Grigg H (1991) Phenology in Calanus finmarchicus; hypotheses about control mechanisms. Mar Ecol Prog Ser 72: 79-91.

Mishima S, Henmi Y (2008) Reproduction and embryonic diapause in the hermit crab Pagurus nigrofascia. Crustacean Research 37: 26-34.

Moriyasu M, Lanteigne C (1998) Embryo development and reproductive cycle in the snow crab, Chionoecetes opilio in the Gulf of St. Lawrence, Canada. Can J Zool 76: 2040-2048.

Mura M, Orru F, Cau A (2006) Reproduction strategy of the deep-sea hermit crabs Pagurus alatus and Pagurus excavatus of the Central-Western Mediterranean Sea. Hydrobiologia 557: 51-57.

Petersen S, Anger K (1997) Chemical and physiological changes during the embryonic development of the spider crab, Hyas araneus L. (Decapoda: Majidae). Comp Biochem Physiol 117B: 299-306.

Stross RG (1969) Photoperiod control of diapause in Daphnia. II. Introduction of winter diapause in the Arctic. Biol Bull 136: 264-273.

Stross RG, Hill JC (1965) Diapause induction in Daphnia requires two stimuli. Science 150: 1462-1464.

Wada S, Goshima S, Nakao S (1995) Reproductive biology of the hermit crab Pagurus middendorffii (Anomura: Paguridae). Crustacean Research 24: 23-32.

Wada S, Kitaoka H, Goshima S (2000) Reproduction of the hermit crab Pagurus lanuginosus and comparison of reproductive traits among sympatric species. J Crust Biol 20: 474-478.

Wada S, Mima A (2003) Reproductive characters of the hermit crab Pagurus proximus Komai, 2000 in Hakodate Bay, southern Hokkaido, Japan. Crustacean Research 32: 73-78.

Wada S, Mima A, Ito A (2005) Reproductive phenology of sympatric hermit crabs in temperate Japan. J Mar Biol Assoc UK 85: 889-894.

Wear RG (1974) Incubation in British decapod Crustacea, and the effect of temperature on the rate and success of embryonic development. J Mar Biol Assoc UK 54: 745-762.

Webb JB, Eckert GL, Shirley TC, Tamone SL (2007) Changes in embryonic development and hatching in Chionoecetes opilio (Snow Crab) with variation in incubation temperature. Biol Bull 213: 67-75.

Westin L, Gydemo R (1986) Influence of light and temperature on reproduction and moulting frequency of the crayfish, Astacus astacus L. Aquaculture 52: 43-50.

Yamada K, Miyazaki K, Tomiyama T, Kanaya G, Miyama Y, Yoshinaga T, Wakui K, Tamaoki M, Toba M (2018) Impact of sea spider parasitism on host clams: susceptibility and intensitydependent mortality. J Mar Biol Assoc UK 98: 735-742. 